\title{
АНАЛИЗ УРОВНЯ ВОВЛЕЧЕННОСТИ СТОРОН В ПЕРЕГОВОРЫ - НЕОБХОДИМОЕ УСЛОВИЕ ПРИМЕНЕНИЯ ОТВЕТСТВЕННОСТИ ЗА НЕДОБРОСОВЕСТНОЕ ВЕДЕНИЕ ПЕРЕГОВОРОВ
}

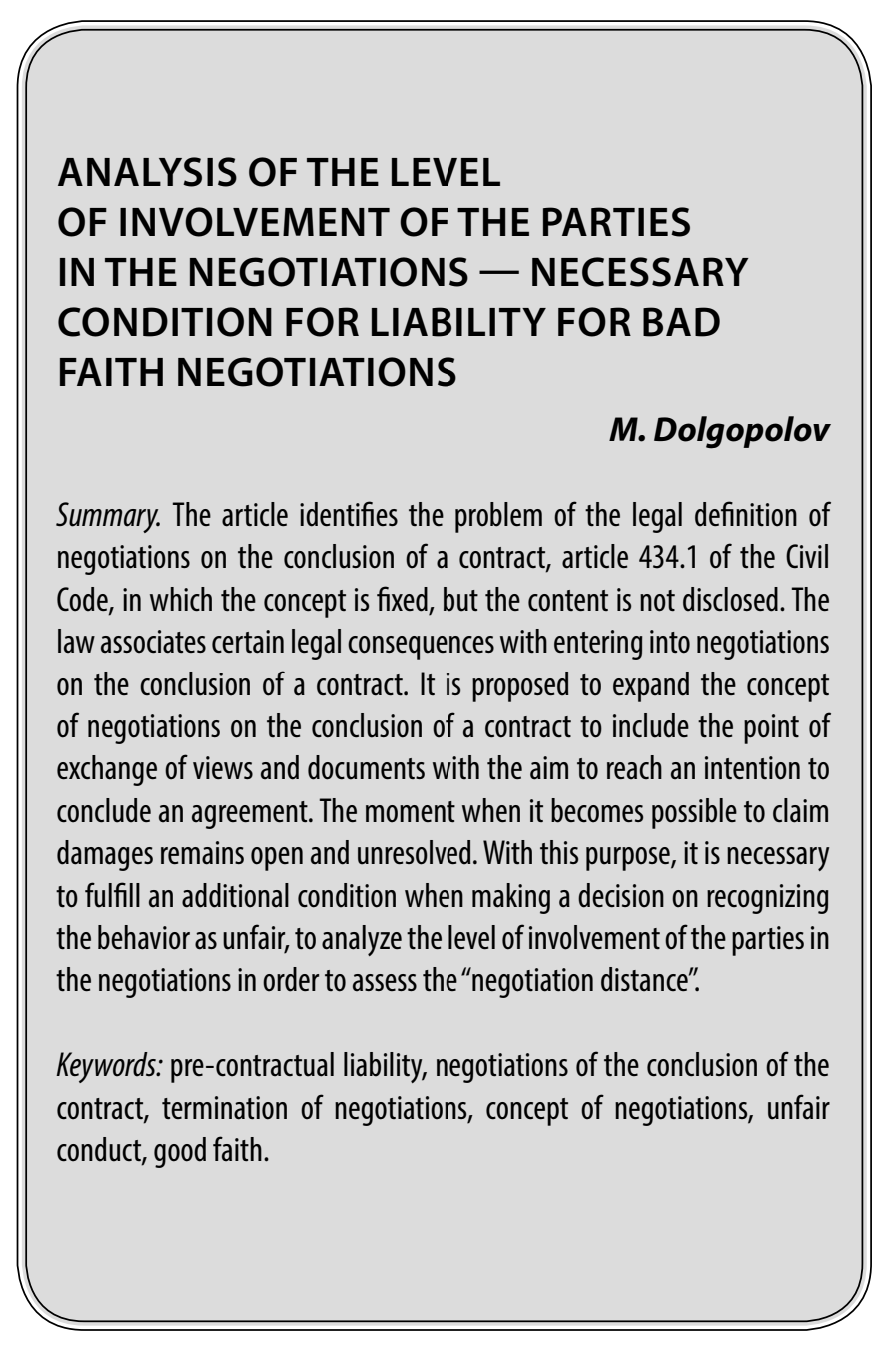

O тветственность за недобросовестное ведение переговоров предусмотрена статьей 434.1 ГК РФ «Переговоры о заключении договора», в которой установлен перечень оснований ответственности. Закон содержит пять поименованных случаев, за которые возможно привлечь контрагента к преддоговорной ответственности. Перечень не является исчерпывающим, в силу абзаца 1 пункта 3 статьи 434.1 ГК РФ всякое проявление недобросовестности на преддоговорном этапе влечёт право на предъявления иска. Для взыскания убытков вызванных недобросовестным ведением переговоров можно применять также общие нормы гражданского законодательства - статьи 1 и 10 ГК РФ, в совокупности с нормами главы 59 ГК РФ.

\author{
Долгополов Михаил Николаевич \\ Соискатель, Институт государства и права \\ Российской академии наук Россия, г. Москва \\ magisterobi-wan@mail.ru
}

Аннотация. В статье обозначена проблема правового определения переговоров 0 заключении договора, статья 434.1 Гражданского кодекса, в котором закреплено понятие, но не раскрыто содержание. С вступлением в переговоры о заключении договора закон связывает определённые правовые последствия. Предложено расширить понятие переговоров 0 заключении договора с включением следующего: обмен мнениями и документами с целью достичь намерения заключить соглашение. Открытым и не решенным остается момент, с наступлением которого возможно требовать возмещения убытков. С этой целью требуется выполнить дополнительное условие при принятии решения о признании поведения недобросовестным, проанализировать уровень вовлеченности сторон в переговоры, чтобы оценить «переговорную дистанцию».

Ключевые слова: преддоговорная ответственность, переговоры 0 заключении договора, прекращение переговоров, понятие переговоров, недобросовестное поведение, добросовестность. 
страивания теории преддоговорной ответственности не только определиться с тем, что считать переговорами, но и с тем, с какого момента сторона переговоров может заявить требование о возмещении преддоговорных убытков, вызванных недобросовестным поведением контрагента.

Разработка и внедрение правил, применимых к конструкции преддоговорной ответственности имеет определяющее значение для конструкции в целом. Если констатировать утверждение, что сам факт вступления в переговоры порождает возможность быть привлечённым к гражданско-правовой ответственности, то такой подход откроет «ящик Пандоры» в арбитражном судопроизводстве и в стабильности экономического оборота. Прослеживается серьёзное упущение законодателя и вышестоящих судов, которые не поставили основания возникновения преддоговорной ответственности в зависимость от какого-либо дополнительного критерия, который послужит катализатором для определения правомерного и неправомерного поведения. Статья 434.1 ГК РФ указывает, что переговоры о заключении договора должны вестись добросовестно и приведен общий перечень недобросовестных действий. Особенность правовой природы преддоговорной ответственности состоит в том, что действие может являться формально недобросовестным, но при этом не должно иметь правовых последствий. Этим и объясняется необходимость наличия дополнительного критерия, который позволит определить возможно ли возмещение убытков в конкретной спорной ситуации.

Итак, важным является определение метода (подхода), который следует использовать для перевода отношений сторон по заключению договора из области ни к чему не обязывающих - к отношениям, признаваемым и защищаемым. Определение такого подхода имеет основополагающее значение, так как именно с переходом переговоров на «повышенный» уровень возможно говорить об ответственности, вытекающей из этих переговоров.

Следует особо указать на обстоятельство, при котором недобросовестное действие (бездействие) должно рассматриваться именно как правонарушение - только при наличии между сторонами определённой взаимосвязи о существе будущего договора или, исходя из заверений и гарантий контрагента, что такие отношения между сторонами существуют или будут существовать.

Видится совершенно оправданным, в настоящий момент, отсутствие в законодательстве понятия переговоров о заключении договора, нецелесообразно создавать рамки столь общему термину, пока теория и практика самостоятельно не выработали его. Но для последова- тельного изучение вопроса нужно установить, что переговоры в юридическом аспекте целесообразно рассматривать как максимально ёмкое и гибкое понятие. Законодатель, как указано выше, говорит - переговоры должны быть посвящены заключению договора и должны проводиться добросовестно.

Толковый словарь Ожегова определяет переговоры как обмен мнениями с деловой целью [5, с. 502]. Деловая цель в юридической интерпретации - это заключение договора. Поскольку договор по ст. 420 ГК РФ определяется через соглашение, следовательно, положения о преддоговорной ответственности должны применяться и к тем случаям, когда законодатель для выражения акта, регулирующего правоотношение сторон, использует термин соглашение.

Переговоры о заключении договора могут быть определены как добросовестный обмен участниками позициями о предмете, о возможности заключения и исполнения, об условиях (общих, существенных и специальных) соглашения, включая запросы и ответы о значимой для заключения информации, что должно послужить созданию цели, в виде намерения достигнуть соглашения по всем условиям.

Таким образом, всякий контакт с другим участником предпринимательской деятельности и последовавший ответ, могут рассматриваться как переговоры о заключении договора. И совершенно не обязательно, чтобы вступающие в переговоры стороны имели намерение заключить договор. Перед участником может стоять цель не само соглашение, а его условия, выявив которые он сможет принять решение заключать ли соглашение, есть ли смысл в дальнейших переговорах, именно поэтому в качестве цели переговоров выступает не согласованный документ, а стойкое намерение его согласовать. Документ не цель переговорного процесса, а результат. При наличии обоюдного желания договориться компромисс может быть выработан с высокой долей вероятности.

Когда в силу п. 5 ст. 434.1 ГК РФ заключается соглашение о порядке ведения переговоров, к процессу заключения этого соглашения подлежат применению правила об ответственности за недобросовестное ведение переговоров. Следует обратить внимание, как только соглашение о ведении переговоров уже заключено, ответственность из такого соглашения нельзя рассматривать как преддоговорную, ибо стороны согласовали обязательство по ведению будущих переговоров и, следовательно, эти отношения в урегулированной соглашением части, будут уже договорными, а ответственность в таком случае должна быть за нарушение принятых обязательств. В.С. Комарицкий предлагает рассматривать 
ответственность из преддоговорных соглашений и как договорную, и как преддоговорную. В качестве обоснования приводятся, скорее формально-логические доводы, чем правовые, а именно - предварительное соглашение это по признакам договор, значит и ответственность договорная, но поскольку предварительное соглашение это не тот договор, который намереваются заключить стороны переговоров, то следовательно ответственность является одновременно и преддоговорной [4, с. 104]. Ошибочность вывода, помимо признания одной категории двумя разными, кроется, по нашему мнению, в самом обосновании, ведь заключая предварительное соглашение стороны имеют волю на заключение именно этого соглашения со своим предметом и существенными условиями. Таким образом ответственность из предварительного соглашения должна рассматриваться как ответственность за нарушение именно этого соглашения без привязки к «другому» договору (который видимо рассматривается как основной).

Обсуждаемый и предлагаемый в настоящей работе подход применим именно тогда, когда стороны никаким образом не регламентировали свои отношения или к обстоятельствам не урегулированным соглашением.

Определение момента, с которого запустится «маховик» преддоговорной ответственности задача крайне трудоёмкая. Вопросу этому не уделяется особого внимания в национальной юридической литературе. Авторами делается упор на обсуждение природы и содержания понятия добросовестности, а поведение, идущее в разрез с принципом доброй совести, рассматривается как противоправное. Особенно активно ученые пытаются обосновать договорную, деликтную или иную природу преддоговорной ответственности.

Отсутствие поставленного вопроса и дискуссии по проблеме наступления предусмотренных преддоговорной ответственностью последствий, приводит к тому, что делаются следующие выводы: «всякое вступление в переговоры о заключении любого договора является юридическим фактом, порождающим права и обязанности на стадии переговоров» [1, с. 162]. Относительно свежий вывод можно найти в статье А.В. Демкиной, согласно которому всякое достаточно определённое действие, выражающее намерение вступить в переговоры и корреспондирующие определённые действия другой стороны являются основанием для возникновения обязательства на преддоговорной стадии, любое нарушение этого обязательства должно нести за собой последствия вне зависимости от близости заключения договора [2, с. 111-112]. Также имеется позиция В.С. Комарицкого, который полагает, что для преддоговорной ответственности достаточно встречных волеизъявлений, для иллюстрации, приводится - ответ на оферту, направленную потенциальным контрагентом, с получением которого стороны входят в названную автором «правовую» стадию отношений [4, с. 102-103].

Отметим, что позиция К.В. Гницевича была сделана во времена Концепции развития гражданского законодательства РФ, когда только возникало обсуждение конструкции преддоговорной ответственности. Аргумент является однозначно верным, начиная переговорный процесс на участников возлагается обязанность действовать добросовестно. Тезисы А.В. Демкиной и В.С. Комарицкого выдвинуты после внесения соответствующих изменений в Гражданский Кодекс РФ. Проблема определения момента, с которого нужно считать сторону правонарушителем, очень хорошо видна на выводах А.В.Демкиной. Поскольку законодатель не поставил степень (уровень) вовлечённости в переговоры как необходимый элемент для признания действия правонарушением, делается вывод, что всякое вступление в переговоры о заключении договора влечёт ответственность в случае нарушения установленной обязанности по добросовестному поведению. B.С. Комарицкий, разделяет правовую и не правовую стадию ведения переговоров, однако, дальнейшего развития тема не получила.

В современной отечественной юридической науке отсутствует чёткое понимание, что не всякое действие, которое можно расценить как формально недобросовестное поведение, должно таковым квалифицироваться. Таким образом и происходит посягательство на основы договорного и предпринимательского права - принцип свободы договора. При этом возможна и полностью противоположная ситуация - жёсткое ограничение и подавление статьи 434.1 ГК РФ статьёй 421 ГК РФ.

Имеющийся в законодательстве способ заключения договора через конструкцию оферта-акцепт не в состоянии придать надлежащую квалификацию понятию «переговоры о заключении договора», выступая в роли «мастер модели», описывающей наиболее общий способ заключения договора. Можно утверждать «мастер модель» оферта-акцепт была необходима для защиты участников гражданско-правового оборота во времена отсутствия подхода, позволяющего применять ответственность до заключения соглашения. В случае с ответственностью за недобросовестное ведение переговоров необходимо не только определить поведение как добросовестное или недобросовестное, а в дополнение к этому проанализировать вовлечённость сторон в переговоры о заключении договора. Только отталкиваясь от анализа уровня вовлечённости в переговоры, и о «переговорной дистанции», можно делать вывод о добросовестности или недобросовестности стороны переговоров. 
Потребность в разграничении этапов переговорного процесса хорошо прослеживается на примере Нидерландов. Где судом в 1982 году в деле Plas/Valburg было установлено 3 стадии переговоров, от каждой стадии которых зависят последствия преддоговорного нарушения. На первой стадии стороны могут свободно покидать переговоры без риска ответственности. Вторая стадия приводит к необходимости возместить расходы в случае выхода стороны их переговоров. Третья стадия, когда характер взаимоотношений сторон показывает, что договор однозначно будет заключён, на что разумно полагается сторона переговоров, прервать переговоры невозможно. В таком случае, судья вместо взыскания убытков может обязать стороны довести переговоры до заключения договора. Позднее, в 1996 году в деле De Ruiterij/Ruiters жесткость третьей стадии была пересмотрена, сторона, желающая отказаться от договора, должна обосновать разумность отказа от договора в связи с существенным изменением обстоятельств (это не снимает всю ответственность, но самые жесткие последствия не применяются) [6, с. 46-49].

Вводить идентичную градацию в российское правовое поле будет ошибочным, однако, на этом примере в должной мере прослеживается, что суд должен оценивать уровень переговоров сторон. Стадии предполагают наличие рамок и переходных ступней, то есть создание дополнительных ограничений для применения конструкции преддоговорной ответственности. Если установить стадии ведения переговоров, то стороны будут искать способ как приблизить или отодвинуть наступление следующей стадии, во избежание риска привлечения к ответственности. Суды будут строго формально воспринимать имеющие стадии, отказывая в защите в тех случаях, когда стороны не достигли той или иной стадии переговоров. Для данного вида ответственности необходимо использовать универсальные формулы, гибкие, одной из таких формул является анализ уровня вовлеченности сторон в переговорный процесс.

Приведём следующий пример, который иллюстрирует, что несмотря на правовую позицию Верховного суда РФ, в соответствии с которой, преддоговорная ответственность не ставится в зависимость от стадии ведения переговоров [7, пункт 30] Арбитражным судом города Москвы прямо указано, что переговоры не продвинулись дальше начальной стадии [8, с. 10]. Оценка судом стадии ведения переговоров подтверждает сделанный нами вывод о необходимости при рассмотрении споров об ответственности за недобросовестное ведение переговоров использовать метод, который позволит проанализировать взаимодействие между сторонами. Исходя из содержания Решения от 24 августа 2020 года по указанному делу суд произвёл именно анализ уровня вовлечённости сторон в переговорный процесс.
Высшая судебная инстанция, пытаясь отстоять принцип свободы договора и осознавая, что нельзя ставить наступление преддоговорной ответственности только в зависимость от недобросовестного поведения, создала правовую позицию - выход из переговоров без объяснения причин на поздней стадии переговоров не свидетельствует о противоправности и недобросовестности [7, пункт 30]. При этом судом не предложен механизм для реализации предусмотренных статьёй 434.1 ГК РФ положений, механизм для разграничения добросовестного выхода из переговоров от недобросовестного.

Без анализа вовлечённости в переговоры конструкция преддоговорной ответственности может походить на «конвейер» по взысканию преддоговорных убытков. Или же превратится в номинальную норму, как это было, например, с положениями об обществах с дополнительной ответственностью, что с учётом практики и происходит в настоящее время. Схожую и актуальную проблему поднял в своей статье Х.В. Идрисов [3, с. 98-105] на примере нескольких судебных дел, которые, по его мнению, служат примером необоснованного обращения К ст. 434.1 ГК РФ. Предложено абсолютно грамотное решение проблемы - заключать предварительные соглашения. С практической точки зрения подобная позиция однозначно верна, ей следует руководствоваться, вступая в сложные переговоры при нынешнем состоянии разработанности и изученности вопроса преддоговорной ответственности. Однако предложение не решает проблему в научном плане.

Анализ уровня вовлечённости сторон в переговоры о заключении конкретного договора - это, обусловленная правовой природой преддоговорной ответственности, обязанность суда при решения вопроса, есть ли в действиях стороны правонарушение. Предлагается не создавать стадии переговоров, а оценивать взаимоотношение сторон в конкретных переговорах о заключении договора исходя из имеющейся деловой активности, корреспонденции и характера (формы, курса) самих взаимоотношений, чтобы иметь возможность оценивать «переговорную дистанцию». «Переговорная дистанция» позволит определить достаточно ли стороны переговоров сблизились при обсуждении будущей сделки, были ли созданы условия для наличия уверенности в том, что сделка будет заключена. Сохранение дистанции подразумевает, что не создаются предпосылки к осуществлению преддоговорных расходов, и тем более, таких расходов, которые направлены на исполнение незаключённого контракта.

Переговоры о заключении договора могут продвинуться на самую решающую стадию, но «переговорная дистанция» может быть на уровне начала переговорного процесса. Такой подход будет обеспечивать право 
участника переговоров отказаться от них в любой момент, не нарушая требования добросовестности. На примере Нидерландов видно, что их система приравнивает стадии ведения переговоров к стадиям заключения договора. Думается, что это осознанный подход. Продвигаясь по стадиям заключения договора стороны утрачи- вают элементы договорной свободы. Российская модель преддоговорной ответственности видится совершенно иначе, она устанавливает не ограничения принципу свободы договора, а предусматривает варианты, где права и свободы одного субъекта могут причинить вред правам и свободам другого.

\section{ЛИТЕРАТУРА}

1. Гницевич К.В. Преддоговорная ответственность в гражданском праве (culpa in contrahendo). Дисс. к.ю.н., СПб, 2009.

2. Демкина А.В. Основания возникновения преддоговорного обязательства // Журнал Российского права, 2017 , № 1.

3. Идрисов Х.В. Проблемные вопросы преддоговорной ответственности: доктринальные подходы и позиции судебной практики // Lex russia, 2018 , № 10.

4. Комарицкий В.С. Правовое регулирование преддоговорной ответственности по законодательству Российской Федерации. Дисс. к.ю.н., М, 2016.

5. Ожегов С.И., Шведов Н.Ю. Толковый словарь Русского языка. 4-е изд. 000 «А Темп», М., 2006.

6. Precontracrual Liability in European Private Law ed. by J. Cartwright and M. Hesselink. Cambridge University Press, 2008.

7. Обзор судебной практики Верховного суда РФ № 1 (2020). Утв. Президиумом Верховного Суда РФ 10.06.2020 // СПС «Консультант Плюс».

8. Решения Арбитражного суда города Москвы от 24 августа 2020 года по делу N A40-98757/2018. Доступно по ccылке: https://kad.arbitr.ru/Document/ Pdf/1aa498e1-68b5-407e-a1a9-bc06f3fc0c19/338f62ce-e015-4ea6-bea2-c1a016fc6a86/A40-98757-2018_20200824_Reshenija_i_postanovlenija. pdf?isAddStamp=True (дата обращения 13.04.2021).

( С Долгополов Михаил Николаевич ( magisterobi-wan@mail.ru ).

Журнал «Современная наука: актуальные проблемы теории и практики»

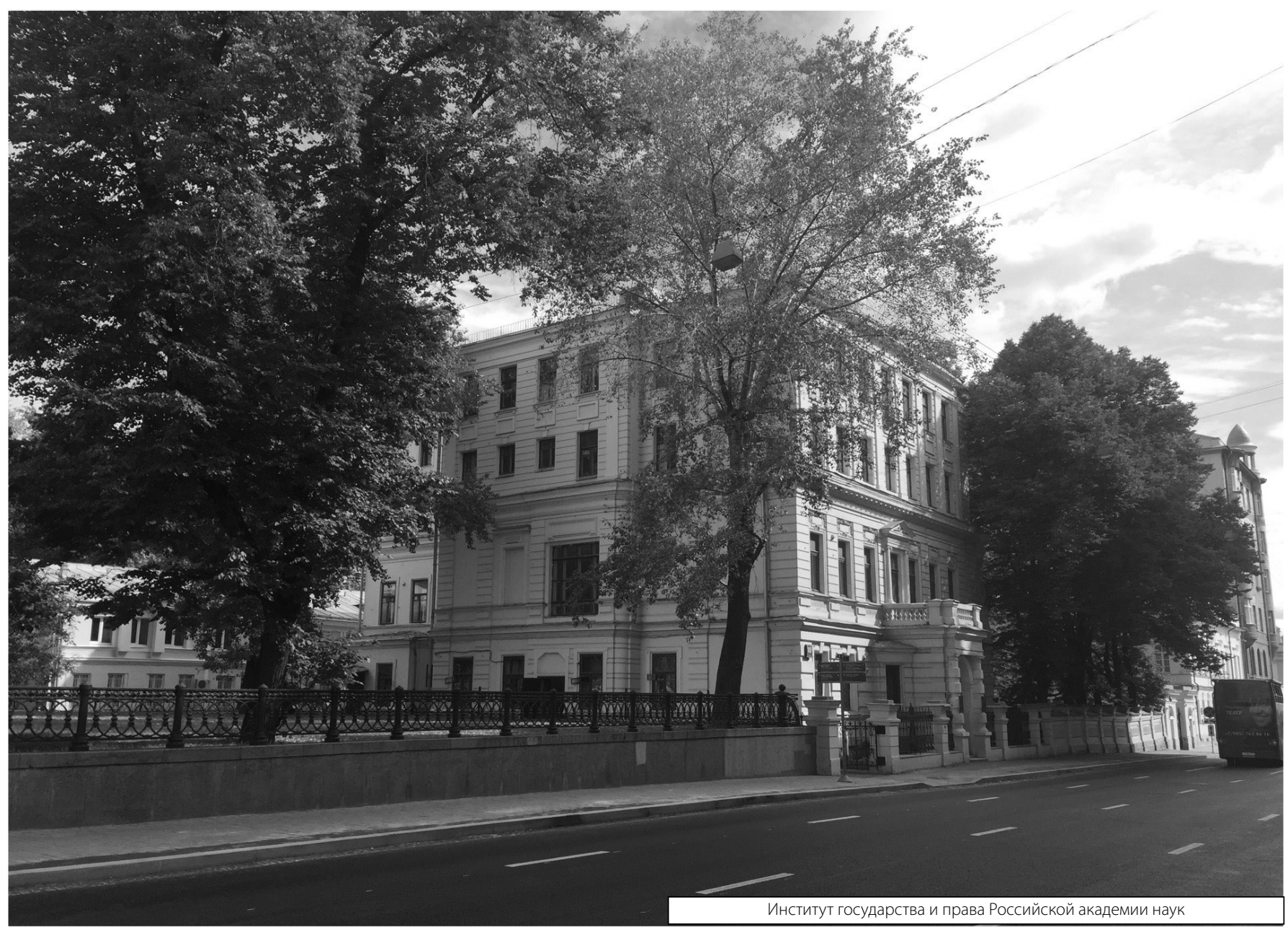

